\title{
O twitter como esfera pública: como foram descritos os candidatos durante os debates presidenciais do $2^{\circ}$ turno de 2014 ? $^{1}$
}

Twitter as public sphere: how were the presidential candidates described during the debates in the presidential election's second round in 2014 ?

Raquel Recuero*

Universidade Católica de Pelotas (UCPEL)

Pelotas, Rio Grande do Sul / Brasil

Universidade Federal do Rio Grande do Sul (UFRGS)

Porto Alegre, Rio Grande do Sul / Brasil

RESUMO: O presente artigo discute como o Twitter, enquanto esfera pública, reproduz discursos que descrevem os candidatos a presidência, Aécio Neves (PSDB) e Dilma Rousseff (PT), durante três debates presidenciais do segundo turno das eleições de 2014. Através de análise de contingência e de análise de redes sociais, discutimos um conjunto de dados obtido de forma automática da API do Twitter. Nossos resultados apontam para descriçōes negativas de ambos os candidatos, notadamente com relação à Dilma. Enquanto Aécio Neves recebe críticas relacionadas à sua atuação nos debates, Dilma Rousseff é criticada principalmente quanto a seu aspecto físico, e também quanto à sua capacidade intelectual e, por fim, quanto à sua atuação nos debates. Esses resultados apontam para uma tendência à presença de violência de gênero nos comentários negativos, focando preconceitos quanto à mulher no caso de Dilma. PALAVRAS-CHAVE: Ofensas; discurso; Twitter; eleiçōes; descrições.

\footnotetext{
* raquel@raquelrecuero.com

${ }^{1} \mathrm{O}$ presente trabalho foi realizado com o apoio do CNPq (projetos 300567/2013-8; 408650/2013-3) e da FAPERGS (projeto 12/1878-5).
} 


\begin{abstract}
The following paper discusses how Twitter, as a public sphere, reproduces discourses that describe the presidential candidates Aécio Neves (PSDB) and Dilma Rousseff (PT) during the three presidential debates in the second round of the Brazilian elections of 2014. We use contingency analysis and social network analysis in order to discuss the data gathered from Twitter API. Our results point to negative descriptions of both candidates, mostly focusing on Rousseff. While Neves was criticized for this performance during the debates, Rousseff was mostly criticized for her body and physical aspect, followed by her intellectual capacity, and finally, for her performance. Thus, the results indicate a gender bias in the derogatory comments and prejudice against women in Rousseff's case.
\end{abstract}

KEYWORDS: Offense; discourse; Twitter; elections; descriptions.

\title{
1 Introdução
}

As campanhas presidenciais das eleiçôes de 2014 foram massivamente construídas em mídia social ${ }^{2}$. Todos os candidatos à presidência mantiveram contas oficiais no Twitter e no Facebook, utilizando os sites de rede social diariamente em suas campanhas (Recuero, Bastos \& Zago, 2016), buscando atuar de forma próxima a seus eleitores. Isso é particularmente relevante quando observamos que, de acordo com os dados do $\mathrm{CGI}^{3}$, $77 \%$ da população que utiliza internet no Brasil (em torno de $50 \%$ da população total) utilizava, em 2013, a rede para atividades de comunicação, notadamente, "participar de redes sociais" (CGI, 2013, p. 179). Em algumas faixas etárias, especialmente as mais jovens, este número cresce para quase $90 \%$. Ou seja, com a amplitude de acesso e a participação online tanto de candidatos quanto de eleitores, vimos na mídia social uma arena política, onde a circulação de diversos discursos é capaz de influenciar as decisōes de voto dos eleitores.

Um dos maiores exemplos desta participação deu-se durante os debates presidenciais, quando vimos a quantidade de eleitores presentes na mídia social buscando debater e discutir os candidatos e suas propostas. Diante desta discussão, parece-nos relevante que sejam estudados os discursos

\footnotetext{
${ }^{2} \mathrm{O}$ conceito de mídia social aqui utilizado remete ao uso dos sites de rede social (tais como o Facebook e o Twitter) como canais midiáticos, mas de forma oposta à mídia de massa, ou seja, no modelo muitos - muitos, mais do que um- muitos.
}

${ }^{3}$ Comitê Gestor da Internet 
construídos na mídia social sobre os candidatos. Assim, buscamos neste trabalho compreender, analisar e discutir os discursos constituídos sobre os então candidatos à presidência da República Dilma Rousseff e Aécio Neves, no período que antecedeu ao $2^{\circ}$ turno das eleiçôes de 2014. De forma específica, analisaremos dados referentes ao que foi dito sobre os candidatos no Twitter, durante três debates que foram televisionados (os debates da TV Record, TV Bandeirantes e TV Globo). Nossas questôes de pesquisa, deste modo, são: 1) Quais discursos foram mais fortes a respeito da descrição dos candidatos? 2) Quais as diferenças e semelhanças dessas descrições, especialmente no que tange a um possível tom ofensivo?

Para discutir esses dados, coletamos de forma automática cerca de 100 mil tweets que utilizaram as hashtags ${ }^{4}$ propostas pelos canais para discutir os eventos. Dentro deste conjunto de dados e utilizando alguns critérios que serão apresentados na parte metodológica, recortamos tweets que descreveram os candidatos Dilma e Aécio e realizamos uma análise de conteúdo de foco quantitativo (Análise de Contingência) e a esses dados, aplicamos métricas de Análise de Redes Sociais.

\section{Esfera Pública, Discurso e Twitter}

O discurso político e sua circulação são fundamentais para a democracia. As várias teorias sobre decisão de voto mostram que a circulação de informações sobre os candidatos é fundamental para a escolha do eleitor. Neste sentido, por exemplo, as chamadas "teorias da escolha racional" (como o trabalho de Downs, 1957), por exemplo, discutem que esta é uma escolha racional, baseada em argumentação e retórica, de fundamentação econômica. Já as chamadas "teorias sociais" (como o trabalho de Lazarsfeld, Berelson \& Guadet, 1948) apontam para a decisão de voto baseada em um contexto social, com influências provenientes dos meios de comunicação e dos conteúdos da mídia, que atuariam diretamente na opinião pública. As teorias psicológicas (como o trabalho de Campbell, Converse, Miller e Stockes, 1960), por outro lado, apontam para outros fatores decisórios mais individuais, como a herança partidária familiar ou o envolvimento com vieses políticos na socialização. Mesmo nestes casos, os eleitores são diretamente influenciados pelo que é dito dos candidatos, pelas percepções de suas conexões sociais e mesmo, pela percepção de uma impressão geral

\footnotetext{
${ }^{4}$ Cada debate propôs, durante o evento, via televisão, uma "etiqueta" (hashtag) que identificou o evento para que fosse utilizada na mídia social.
} 
sobre o candidato construída pela "opinião pública”.

O conceito de "opinião pública" é associado ao conceito de "esfera pública" habermasiana neste trabalho. Ou seja, vemos a mídia social como um espaço análogo àquele da "esfera pública" de Habermas (1991), onde as ideias são debatidas, reproduzidas e refutadas, constituindo aí o que se chama de "opinião pública". Essa "opinião" é um constructo imaginário, mas que é resultado de determinados enunciados que constroem discursos que circulam pelo ecossistema social. A opinião pública é fortemente associada ao conceito de esfera pública, um sistema relacionado a áreas de debate que são capazes de produzir opinião pública (Habermas, 1991). A opinião pública, neste contexto, relaciona-se com uma orientação política produzida nesta esfera pública. A esfera pública, assim, constitui-se na sociedade em debate, ao mesmo tempo espaço, ambiente e debate, a partir de quatro requisitos: 1) a formação da opinião pública; 2) o acesso a todos os cidadãos; 3) a possibilidade de reunião e discussão de questôes de interesse; 4) o debate sobre as regras que governam as relações.

A comparação de sites de rede social como o Twitter com a construção de uma esfera pública no sentido de Habbermas não é nova (CONOVER et. al., 2011; Bastos, 2011) e tem sido consistentemente reconstruída por vários trabalhos dedicados a investigar a mídia social e seu papel em debates políticos. Bastos (2011) usa o conceito de "digital media matrix", baseado no trabalho de Finnemann (2001), para se referir a essa esfera pública online. $\mathrm{O}$ autor trabalha com a metáfora da cebola para mostrar como os diferentes canais (blogs, twitter e etc.) atuam como infraestrutura técnica, formando clusters de opiniōes que se propagam ou não na rede. Essa ideia é muito importante porque na mídia social, ao contrário da mídia de massa, a audiência só tem contato com a mensagem se os milhares de intermediários que fazem o trabalho de gatekeeping a repassarem para suas redes. No caso deste estudo, observamos um ecossistema midiático, onde os debates na televisão são discutidos, enquanto acontecem, no Twitter. Essas mensagens são compartilhadas, reproduzidas e discutidas pelos eleitores, ao mesmo tempo em que os candidatos e suas assessorias e militâncias também tentam influenciar esse debate. As mensagens que conseguem receber maior atenção, seja através de retweets ou menções, acabam refletindo discursos com os quais a audiência concorda ou para os quais deseja dar visibilidade. Isso é bastante diferente da mídia tradicional como a televisão, por exemplo, onde a mensagem de um determinado candidato passa para toda a audiência. $\mathrm{Na}$ 
mídia social, como o Twitter, ela depende dos seguidores do candidato a reproduzirem para então atingir uma rede maior. Deste modo, a expectativa é que os discursos políticos que constituem e são constituídos pela opinião pública circulem e tenham impactos diferentes nessas ferramentas.

O trabalho de Conover et al. (2011), por exemplo, trouxe fortemente a questão da polarização durante as eleiçôes de 2010 no Twitter, e mostrou como a ferramenta funcionou como estrutura para os debates sobre as eleições, apontando como as redes de retweets, especialmente, são muito polarizadas. Trabalhos em outras esferas e outras partes do mundo também apontam o potencial da ferramenta para a discussão eleitoral. Conover $e t$ al. (2011b), analisam o conteúdo dos tweets das redes de discussão das eleições americanas e apontam que este conteúdo pode atuar como um preditor de filiação política. Isso significa que usuários com uma determinada filiação política tendem a retuitar mais mensagens com as quais concordam (ou alinham-se politicamente) do que mensagens contrárias. A prática de retweets em contextos políticos também é análoga à da panfletagem, uma prática identificada por Bastos, Travitski e Raimundo (2013). Ou seja, as hashtags tendem a funcionar também como modos de propaganda política para ativistas. Assim, parte dessas práticas podem ser importantes, pois também podem ser tentativas de influenciar o debate contra ou a favor de um determinado candidato.

Outra ideia importante é a que a esfera pública constituída no Twitter também tem relações de poder que influenciam a propagação de determinadas mensagens em detrimento de outras. Essas relações de poder também estão relacionadas com as disputas do espaço offline. Por conta desse contexto, o conceito de discurso que utilizamos neste trabalho é aquele atribuído a Foucault, em que este compreende as regras, as "condiçôes da função enunciativa" (1986, p. 43). Esse "poder dizer" está diretamente associado também aos atos de filtragem da mídia social, pois se relaciona com a audiência encontrar eco neste poder e reproduzir aquilo que foi dito. Para Foucault, o discurso está relacionado ao poder e às condiçôes históricas de produção e tem regras. Essas regras constituem sistemas, que são parte do que o autor chama de "formação discursiva". Ou seja, "sempre que se puder descrever, entre certo número de enunciados, semelhante sistema de dispersão e se puder definir uma regularidade (uma ordem, correlações, posições, funcionamentos, transformações) entre os objetos, os tipos de enunciação, os conceitos, as escolhas temáticas, teremos uma formação 
discursiva" (p. 43). Esse sistema de dispersão é fruto de condições de produção e rupturas que, em nosso caso, podem ou não estar ocorrendo na discussão, na esfera pública do Twitter, sobre os debates eleitorais que estão sendo televisionados.

A opinião pública, assim, também é construída e compartilhada na mídia social. Por isso, compreender quais fragmentos e elementos do discurso dominante e quais elementos são reforçados pela audiência é muito importante. A mídia social, através de sites como o Twitter e o Facebook tem papel importante na ampliação dos espaços de debate público, e a sua influência na construção e no desafio do discurso dominante é muito importante (Recuero, 2012). Neste trabalho, escolhemos como estudo de caso específico os tweets que foram publicados sobre os debates dos candidatos a presidência no $2^{\circ}$ turno das eleições de 2014, como recorte de análise. E como dissemos no início, neste recorte questionamos, de modo particular, como os candidatos foram descritos pela audiência nesses três eventos. Ora, enquanto parte desta descrição pode ser positiva, interessa-nos fundamentalmente aquela negativa. Assim, observaremos especialmente os xingamentos e as descrições ofensivas aos candidatos.

O xingamento é uma forma de atribuir elementos socialmente indesejáveis a um determinado sujeito. O trabalho de Zanello, Bukowitz e Coelho (2011) buscou categorizar "xingamentos" de um conjunto de adolescentes, levando em conta elementos como gênero e poder. Esses elementos são essencialmente importantes porque auxiliam a desvelar como a descrição dos candidatos buscou não apenas influenciar a opinião pública no Twitter, mas igualmente construir impressões sobre suas personas e reforçar essas impressōes através dos retweets. A classificação dos autores focou em: 1) traços de caráter (quando o foco é desqualificar o caráter do outro); 2) comportamento sexual (a principal categoria); 3) atributos físicos; 4) atributos intelectuais; 5) família e 6) outros. O potencial ofensivo de cada xingamento também foi avaliado pelos autores. Para as mulheres, os tipos de xingamentos considerados piores pelo público foram aqueles relacionados ao comportamento sexual e aos atributos físicos, seguidos pelo caráter e, por último, os atributos intelectuais. Para os homens, os tipos de xingamento considerados mais ofensivos foram, primeiramente, aqueles associados ao comportamento sexual, seguidos pelos traços de caráter, atributos físicos e atributos intelectuais. Os autores discutem essas diferenças atribuindo-as aos papéis de gênero constituídos na sociedade, notadamente a valorização dos 
atributos físicos para as mulheres e dos atributos intelectuais para os homens, principalmente. Em outro trabalho, Zanello e Gomes (2010) apontam para as diferentes conotações que um mesmo xingamento adquire se atribuído a um homem ou a uma mulher, salientando a necessidade da compreensão semântica de seu uso, especialmente no que toca às relações de gênero. Neste trabalho, as autoras explicam ainda que os xingamentos aos homens tendem a atacar-lhe a "virilidade", comparando-os a atitudes e comportamentos femininos. Já para as mulheres, a quem se reserva a vida privada, as ofensas seriam principalmente relacionadas ao (indesejável) comportamento sexual ativo. $\mathrm{O}$ ato de xingar, assim, relaciona-se diretamente com os papéis de gênero construídos socialmente, regulando-os e atuando como forma de poder regulador sobre as relações. $\mathrm{O}$ xingamento, assim, também reproduz formaçôes discursivas presentes na sociedade, que reforçam elementos do discurso dominante.

Uma vez discutidos os elementos teóricos que embasarão esta análise, passamos à sua descrição metodológica.

\section{Método}

Conforme explicitamos na introdução, este trabalho está focado em duas questões fundamentais de pesquisa. Na primeira, queremos compreender como os candidatos foram descritos nos debates durante a discussão dos mesmos na mídia social. Na segunda, preocupamo-nos com a comparação entre esses dois discursos e a discussão dos possíveis impactos dessas descrições, principalmente aquelas negativas e ofensivas.

Para discutir essas questôes, coletamos através do NodeXL ${ }^{5}$ cerca de 156.660 mil tweets que utilizaram as hashtags ${ }^{6}$ propostas pelos canais para discutir os eventos. Dentro deste conjunto de dados, recortamos tweets que descreveram os candidatos Dilma Rousseff (PT) e Aécio Neves (PSDB) e realizamos uma análise de conteúdo de foco quantitativo (análise de contingência). Os dados coletados foram sumarizados na tabela a seguir (Tabela 1).

\footnotetext{
${ }^{5}$ O NodeXL é uma ferramenta que permite a coleta automática de tweets que contenham um elemento identificador através da rest_API do Twitter.

${ }^{6}$ Cada debate propôs, durante o evento, via televisão, uma "etiqueta" (hashtag) que identificou o evento para que fosse utilizada na mídia social.
} 
Tabela 1: Dados coletados por debate e dia

\begin{tabular}{l|l|c|c}
\hline & \multicolumn{1}{|c|}{ Hashtag } & Data & Total de Tweets \\
\hline Debate Rede Bandeirantes & $\begin{array}{l}\text { \#debateband, } \\
\text { \#debatenaband } \\
\text { e\#debatedaband }\end{array}$ & $14 / 10 / 2014$ & 74701 \\
\hline Debate Rede Record & $\begin{array}{l}\text { \#debaterecord, } \\
\text { \#debatenarecord } \\
\text { e } \\
\text { \#debatedarecord }\end{array}$ & $19 / 10 / 2014$ & 17593 \\
\hline Debate Rede Globo & $\begin{array}{l}\text { \#debateglobo, } \\
\text { \#debatenaglobo } \\
\text { e } \\
\text { \#debatedaglobo }\end{array}$ & $24 / 10 / 2014$ & 64366 \\
\hline
\end{tabular}

Para recortar os dados referentes especificamente às descriçôes dos candidatos, filtramos os tweets a partir das expressões "Dilma é", "Dilma está" e "Aécio é", "Aécio está". Isso significa que apenas tweets que continham essa expressão foram selecionados para a análise, pois o nosso primeiro objetivo foi compreender como os candidatos foram descritos no Twitter. Aqui, portanto, interessam-nos elementos adjetivadores dos candidatos, por isso a escolha pelas expressões. A partir desta delimitação, selecionamos 2487 tweets que continham essas expressões para Dilma e 1157 tweets que continham as mesmas expressóes para Aécio.

A partir deste recorte, constituímos o corpus de análise. Para analisar os tweets, utilizamos análise de contingência, que é uma forma de análise de conteúdo quantitativa, baseada em eleição e classificação de palavras em conceitos e a posterior análise de suas correlaçôes. Os procedimentos metodológicos de análise realizados, portanto, referem-se a:

\section{1) Contagem automática da frequência dos termos no conjunto total de} dados-Nestafasecontamosautomaticamenteafrequênciadetodasaspalavras do conjunto de dados por unidade (o tweet). Assim, por exemplo, o número total de referências a "presidenta" corresponde ao número total de vezes que a palavra apareceu em tweets individuais (mas não dentro do mesmo tweet).

\section{2) Classificação das palavras semelhantes dentro de um mesmo conceito}

- Como interessava-nos compreender como os candidatos eram descritos, conceitos emergiram da classificação de palavras frequentes utilizadas 
com o mesmo sentido. Assim, por exemplo, "irônico" e "ironizou” foram classificadas no mesmo conceito. $\mathrm{O}$ objetivo aqui foi manter ao máximo a variedade dos conceitos para não comprometer a análise, observando-se a junção de palavras utilizadas com o mesmo sentido. Para compreender o sentido, uma amostragem de tweets que utilizou as palavras em questão foi analisada de forma qualitativa. Os conceitos que tiveram uma frequência mínima de dez (10 vezes presentes nos tweets) nos dados compuseram o corpus analisado. Este procedimento faz parte da técnica da análise de conteúdo, que busca classificar os conteúdos e criar categorias de sentido, com a análise de contingência (BARDIN, 2004; OOSGOOD, 1959), que busca analisar conceitos em relação uns aos outros.

3) Análise de rede das coocorrência entre os conceitos - Finalmente, os conceitos foram analisados em relação uns aos outros (coocorrências). Para auxiliar a análise dessas relações entre os conceitos, focamos na análise estrutural, método que busca, através da estrutura de relaçóes em uma rede, compreender a posição de cada nó e a estrutura geral da rede (WASSERMAN \& FAUST, 1994, DEGENNE \& FORSE, 1999). No caso deste trabalho, os nós da rede compreendem os conceitos que construímos nas etapas anteriores, e a estrutura, a rede de coocorrências destes conceitos (ou seja, cada conexão representa uma coocorrência, dois conceitos que ocorriam ao mesmo tempo em uma mesma unidade - o tweet). A representação da rede é construída através de grafos, que são imagens dessas estruturas, onde os nós representam os conceitos e as conexóes, sua coocorrência. As medidas entre os conceitos que serão analisados a partir de métricas da análise de redes, são:

a) Grau - Métrica que avalia o número de conexões que cada conceito recebe (DEGENNE \& FORSÉ, 1999). Quanto maior o número de coocorrências um determinado conceito teve com os demais, mais central ele é. O grau também pode indicar a frequência dos conceitos no grupo de coocorrências. Neste trabalho, o grau representa a frequência do conceito nos dados.

b) Modularidade- Esta métrica utiliza um algoritmo que calcula a probabilidade de um determinado conjunto de conceitos pertencer a um mesmo grupo na rede (grupo de conceitos que tendem a coocorrer entre si) (NEWMAN, 2003). Nos grafos, utilizamos cores para demonstrar a 
modularidade dos conceitos. A tendência de determinados conceitos em aparecer em conjunto pode indicar "formações discursivas" no sentido de Foucault (1986). A modularidade, em tweets, também pode ser influenciada por retweets, o que acaba construindo um conjunto de palavras que está mais fortemente conectada. Para analisar melhor a modularidade dos conceitos, utilizamos também os dados normalizados. A normalização permite reduzir a discrepância entre os conjuntos, dando visibilidade a coocorrências diferentes dos dados gerais, notadamente muito influenciados por um ou outro tweet que recebe muito mais atenção (retweets) na rede.

Para este trabalho, inicialmente contabilizamos a frequência das palavras nos dados totais (em cada unidade, determinada aqui como um tweet). Todos os conceitos com frequência superior a 5 (cinco) foram então classificados dentro de conceitos mais comuns (consultando-se qualitativamente os tweets para tanto) e finalmente, esses conceitos maiores foram analisados em sua coocorrência com outros conceitos. $\mathrm{O}$ resultado será discutido na próxima seção.

\section{Análise}

Nesta seção, passaremos a discutir como os dados mostram a descrição dos candidatos no Twitter.

\subsection{Aécio Neves}

O candidato Aécio Neves obteve, durante os debates, um conjunto de 1157 menções descritivas, que foram analisadas em nossos dados. Conforme apontamos na seção anterior, o foco principal foi a descrição do candidato. Na Figura 1 vemos o primeiro grafo de coocorrências. As cores indicam os módulos (grupos de conceitos que tendem a aparecer mais em conjunto), o tamanho dos conceitos indica sua frequência e as conexões indicam suas coocorrências (quanto mais grossas, maior a ocorrência conjunta dos dois conceitos).

A modularidade dos dados em geral é mostrada no grafo com a presença de dois grupos. O primeiro, o grupo maior e em azul claro, mostra a frequência de um conjunto maior de conceitos. O segundo, menor e em vermelho, mostra um grupo de conceitos que coocorreu repetidas vezes (provavelmente através de retweets). No conjunto de coocorrências, vemos que Aécio é descrito de forma positiva, por um lado, como "preparado", 
"seguro" e "articulado" em maior grau (maior frequência dos conceitos). Em menor frequência, vemos "bom" e "gestor" (que coocorrem entre si), "sorridente", conjuntamente com "bem" e "maior". Ao mesmo tempo, também vemos conceitos negativos, tais como "carente", "velho", "burguês", "canastrão" (associados a "muito") e também "filho" e "preta". No cluster vermelho, vemos as descriçôes centradas em "homem", "arrogante”, irônico", "forte" e "desrespeitoso".

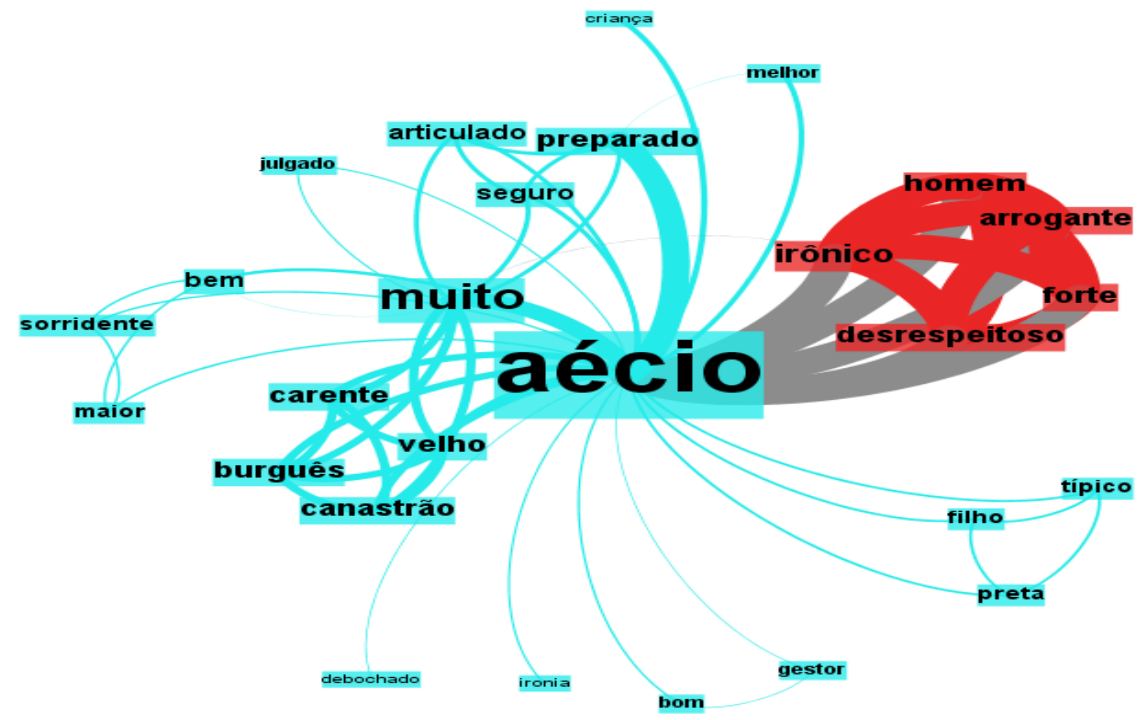

Figura 1: Rede de coocorrências dos conceitos relacionados ao candidato Aécio Neves

No conjunto, vemos grupos de tweets associados a descriçôes positivas do candidato notadamente relacionadas a sua capacidade de gestão ("preparado" e "bom" e "gestor" no mesmo grupo), e seu modo de falar no debate ("articulado" e "seguro") e sua aparência ("sorridente"). As críticas, por outro lado, estão focadas na situação econômica do candidato ("burguês"), em sua descrição física ("forte", "homem"), e em seu modo de falar ou atuação nas câmeras ("canastrão", "arrogante", "irônico" e "desrespeitoso"). Aécio é «velho», também.

A proximidade dos dados de frequência (ou seja, o fato de determinados conceitos que coocorrem estarem muito próximos em termos numéricos) indica que essas coocorrências talvez sejam consequência de um 
grande número de retweets de determinados tweets. Embora a dinâmica do Twitter seja esta, analisaremos os dados normalizados, de forma a reduzir o impacto de um conjunto muito retuitado em relação aos demais conjuntos de coocorrências.

A tabela a seguir (Tabela 2) resume a frequência dos conceitos nos tweets. O número representa o número de vezes que cada elemento descritivo foi utilizado no conjunto total.

Tabela 2: Frequência dos conceitos nos dado

\begin{tabular}{|c|c|c|c|}
\hline N.o & Módulo & Conceitos & Frequencia total \\
\hline \multirow[t]{14}{*}{1} & \multirow[t]{14}{*}{ Azul } & carente & 76 \\
\hline & & velho & 76 \\
\hline & & canastrão & 76 \\
\hline & & burguês & 77 \\
\hline & & debochado & 11 \\
\hline & & preparado & 219 \\
\hline & & seguro & 43 \\
\hline & & articulado & 42 \\
\hline & & sorridente & 21 \\
\hline & & arrogante & 295 \\
\hline & & bom & 19 \\
\hline & & gestor & 10 \\
\hline & & melhor & 46 \\
\hline & & bem & 37 \\
\hline \multirow[t]{5}{*}{2} & \multirow[t]{5}{*}{ Vermelho } & irônico & 297 \\
\hline & & desrespeitoso & 296 \\
\hline & & forte & 293 \\
\hline & & homem & 296 \\
\hline & & arrogante & 295 \\
\hline
\end{tabular}

Ao observarmos as coocorrências normalizadas (Figura 2), vemos as conexôes de forma mais detalhada. Diretamente conectado a Aécio no cluster azul, por exemplo, estão os conceitos "irônico" e "debochado", conjuntamente com "preparado" e "melhor" (Exemplo: "Aécio é irônico na resposta. É o melhor candidato"). Esse cluster mostra como dois discursos, 
um bastante crítico da posição do candidato e outro, bastante positivo, coexistiram durante os eventos. Ao mesmo tempo, à esquerda, em roxo, vemos um conjunto de coocorrências que descreve o candidato como "muito, canastrão, carente, burguês, canastrão, velho e julgado" (como, por exemplo, "É muito canastrão esse Aécio»). No caso, vemos também que ao candidato parece ter sido associado novamente um discurso crítico, provavelmente fruto de retweets de um tweet que continha os conceitos apontados. Em verde, abaixo, os conceitos de "bom e gestor" aparecem agregados (exemplo: "Aécio foi bom gestor em Minas, está preparado."). Os conceitos em vermelho referem-se a um tweet em que se mencionou Aécio e a cantora Preta Gil.

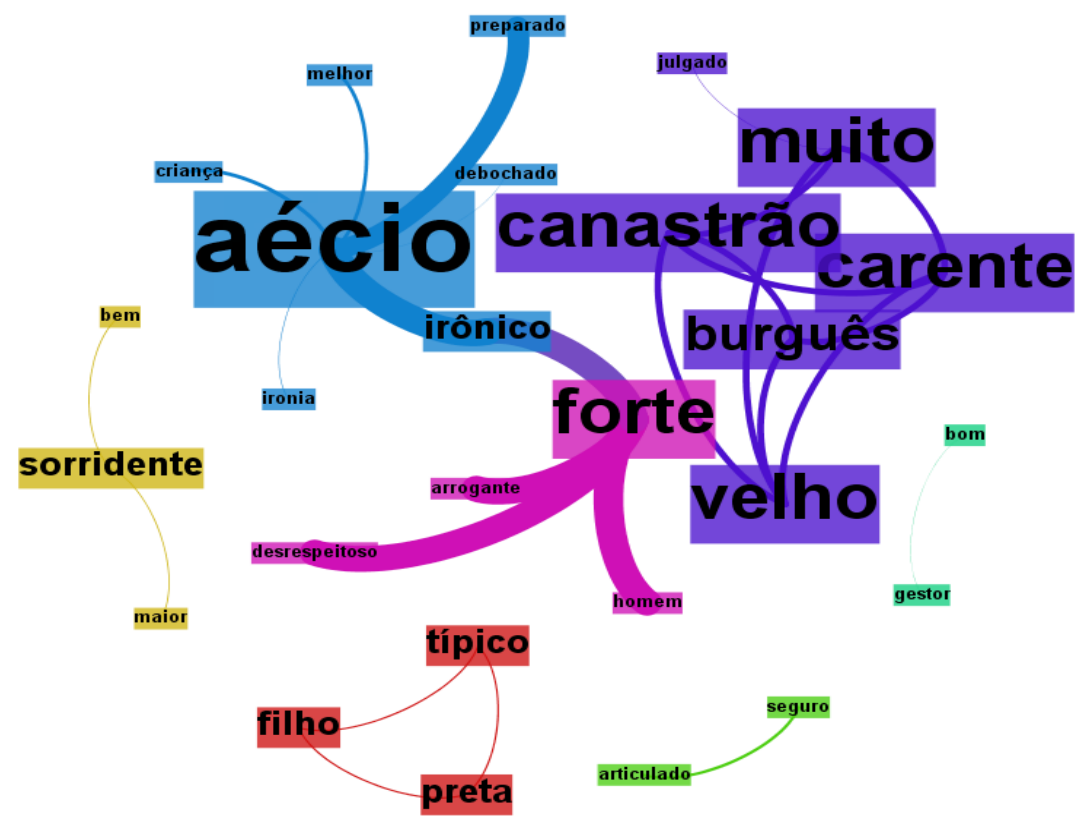

Figura 2: Coocorrências normalizadas dos dados referentes ao candidato Aécio Neves.

As críticas tecidas a Aécio presentes da Figura 2, observadas através dos grupos de conceitos, dizem respeito, primeiramente, à sua atitude nos debates (o que é confirmado na Tabela 3, a seguir). 
Tabela 3: Conceitos utilizados para descrever Aécio Neves

\begin{tabular}{c|c|c|c}
\hline Conceitos & Tom & Crítica & Frequência \\
irônico & Crítica & Atitude no debate & 297 \\
desrespeitoso & Crítica & Atitude no debate & 296 \\
arrogante & Crítica & Atitude no debate & 295 \\
forte & Elogio & Capacidade & 293 \\
preparado & Elogio & Capacidade & 219 \\
burguês & Crítica & Condição social & 77 \\
carente & Crítico & Aspecto Emocional & 76 \\
velho & Crítico & Aspecto Físico & 76 \\
canastrão & Crítica & Atitude no debate & 76 \\
seguro & Elogio & Atitude no debate & 43 \\
articulado & Elogio & Atitude no debate & 42 \\
sorridente & Elogio & Atitude no debate & 21 \\
\hline debochado & Crítica & Atitude no debate & 11 \\
\hline bom gestor & Elogio & Capacidade & 10 \\
idiota & Crítica & Capacidade & 6 \\
sujo & Crítica & Caráter & 5 \\
\hline
\end{tabular}

Nos dados apresentados, observamos uma forte conexão entre críticas relacionadas à atitude do candidato no debate (por exemplo, "\#debateband Aécio não me desce, ele com esse risinho debochado, parece q sempre está com um olhar superior sobre os pobres). Mesmo as críticas realizadas pela militância de Dilma pareceram focar principalmente no desempenho e atitude de Aécio nos debates (exemplo: "[Aécio] é debochado, arrogante e mentiroso. \#MelhorcomDilma”). Críticas com relação à sua aparência física foram raras ("Aécio é um velho"). Ofensas diretas, como "idiota" ou "sujo" apareceram em muito menor presença. Finalmente, críticas com relação à condição social de Aécio também apareceram com frequência ("Aécio é estrategista e coerente, no entanto é um hipócrita mentiroso burguês, nada muda.").

Essa marcação discursiva da crítica é interessante quanto observamos também os elogios, focados na capacidade do candidato ("bom gestor" é um conjunto especialmente emblemático neste sentido). A militância favorável ao candidato, assim, focou seu apoio destacando as capacidades de Aécio e seu desempenho nos debates (exemplo: "Como era esperado, Aécio bem melhor e mais seguro. Os debates serão o pesadelo da Presidente Dilma Rousseff."). Vemos, assim, que enquanto os grafos descreveram as relações 
entre os conceitos (contextos de citação), as tabelas apresentam os dados quantitativos que foram desenhados nas imagens.

\subsection{Dilma Rousseff}

Nesta sessão passaremos a discutir os dados relativos à então candidata Dilma Rousseff, que obteve 2487 mençôes descritivas. Inicialmente, analisamos, dentro dos tweets, as coocorrências entre os principais conceitos, como no caso anterior. A seguir, passaremos às coocorrências normalizadas e, a seguir, aos principais elementos descritivos.

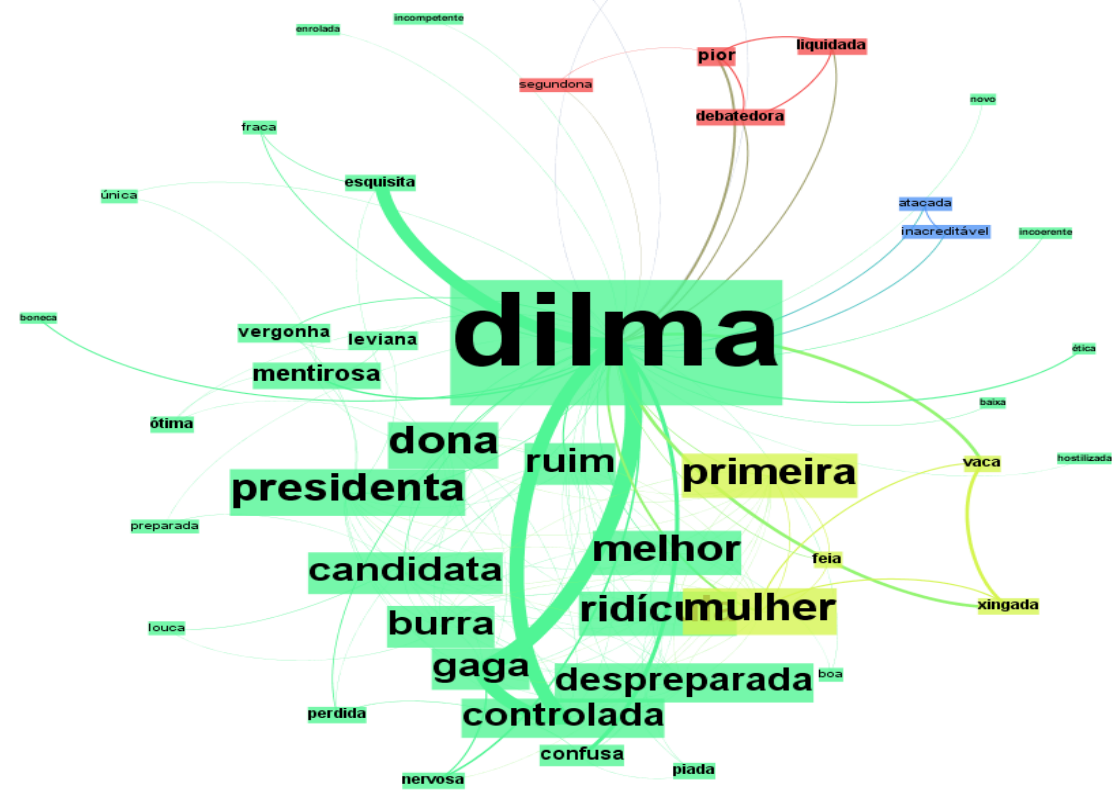

Figura 3: Coocorrências gerais nos dados referentes a Dilma Rousseff.

O grafo mostra a representação dos conceitos em coocorrência em torno da então candidata Dilma. Em verde, ao centro, temos o primeiro módulo. Nele, Dilma é descrita como "dona", "presidenta", "candidata", "ruim", "burra”, "ridícula”, "melhor”, "despreparada”, "gaga”, "controlada”, "confusa”, "piada”, "nervosa”, "perdida”, "vergonha”, "boneca”, "fraca”, “esquisita”, “ótima”, “preparada”, “boa”, “enrolada”, “incompetente, "incoerente", "baixa", "hostilizada" e "louca". No módulo amarelo, é descrita como "primeira”, "mulher”, "feia”, "vaca”, "xingada”. No módulo vermelho, é 
descrita como "segundona", "pior”, "debatedora”, e "liquidada”. No módulo rosa, é descrita como "anã”, "diplomática” e "mula”. Finalmente, no módulo azul, é descrita como "atacada" e "inacreditável”. O módulo verde continha o maior número de descrições associadas a Dilma, embora nem todas fossem associadas entre si (como as conexões demonstram). Entre os conceitos mais associados, estavam "gaga" e "controlada". Estes estão fortemente conectados porque muitos tweets questionaram a capacidade da então candidata, alegando que ela utilizava ponto eletrônico, era controlada pela equipe e portanto, estava gaga (Exemplo: "\#DebatedaBand Ta aqui o ponto eletrônico da Dilma, por isso gaguejava! Dilma é controlada pelo PT! Muito grave!” ). O módulo amarelo revela que os conceitos em questão tenderam a aparecer em tweets em que foram todos relacionados (por exemplo, um dos tweets mais retuitados dizia "Entendem muito de violência contra a mulher. RT @ brasilpost Dilma é xingada de 'vaca' por militantes do PSDB antes do inicio do debate."). Outros tweets, em menor grau, associavam Dilma a "mulher", simplesmente (Exemplo: "Dilma é a primeira mulher feia que Aécio fodeu \#debatedaband"). Outro grupo de associações frequentes derivadas de retweet é o rosa, onde Dilma foi descrita como "anã diplomática, mula sem cabeça kkkkk \#Debatedaband \#AecioPelaMudanca”. O tweet do exemplo foi bastante compartilhado, o que gerou uma forte associação entre os conceitos. Do mesmo modo, o grupo vermelho também trouxe forte associação entre os conceitos "pior debatedora" e "liquidada", conforme o tweet demonstra: "Se fosse Aécio defendendo anos Lula-Dilma contra anos FHC, eleição estaria liquidada. Dilma é pior debatedora em 2os turnos".

A tabela a seguir (Tabela 4) resume a frequência dos conceitos nos dados:

Tabela 4: Frequência dos conceitos usados para descrever Dilma Rousseff.

\begin{tabular}{c|c|c|c}
\hline N.o & Módulo & Conceitos & Frequência total \\
\hline \multirow{3}{*}{1} & Verde & Gaga & 544 \\
\cline { 3 - 4 } & & Controlada & 448 \\
\cline { 3 - 4 } & Esquisita & 428 \\
\cline { 3 - 4 } & Mentirosa & 65 \\
\cline { 3 - 4 } & & Ruim & 49 \\
\cline { 3 - 4 } & & Presidenta & 29 \\
\cline { 3 - 4 } & & Perdida & 34 \\
\hline
\end{tabular}




\begin{tabular}{|c|c|c|c|}
\hline & \multirow[t]{22}{*}{ Verde } & Vergonha & 32 \\
\hline & & Primeira & 28 \\
\hline & & Melhor & 25 \\
\hline & & Candidata & 25 \\
\hline & & Feia & 24 \\
\hline & & Dona & 21 \\
\hline & & Leviana & 16 \\
\hline & & Ridícula & 13 \\
\hline & & Despreparada & 9 \\
\hline & & Piada & 8 \\
\hline & & Ótima & 8 \\
\hline & & Preparada & 8 \\
\hline & & Burra & 5 \\
\hline & & Perdida & 34 \\
\hline & & Boa & 8 \\
\hline & & Incompetente & 8 \\
\hline & & Enrolada & 6 \\
\hline & & Nervosa & 66 \\
\hline & & Fraca & 32 \\
\hline & & Única & 12 \\
\hline & & Boneca & 44 \\
\hline & & Louca & 16 \\
\hline \multirow[t]{3}{*}{2} & \multirow[t]{4}{*}{ Amarelo } & Mulher & 81 \\
\hline & & Primeira & 28 \\
\hline & & Feia & 24 \\
\hline & & Vaca & 112 \\
\hline \multirow[t]{3}{*}{3} & \multirow[t]{3}{*}{ Rosa } & Diplomática & 8 \\
\hline & & Anã & 8 \\
\hline & & Mula & 8 \\
\hline \multirow[t]{4}{*}{4} & \multirow[t]{4}{*}{ vermelho } & Segundona & 12 \\
\hline & & Pior & 80 \\
\hline & & Liquidada & 48 \\
\hline & & Debatedora & 48 \\
\hline \multirow[t]{2}{*}{5} & \multirow[t]{2}{*}{ azul } & Atacada & 40 \\
\hline & & Inacreditável & 40 \\
\hline
\end{tabular}


Novamente, ao observarmos as coocorrências normalizadas, as formações mais comuns (grupos de conceitos que são repassados juntos) aparecem com mais força. É possível identificar contextos de uso dos conceitos.

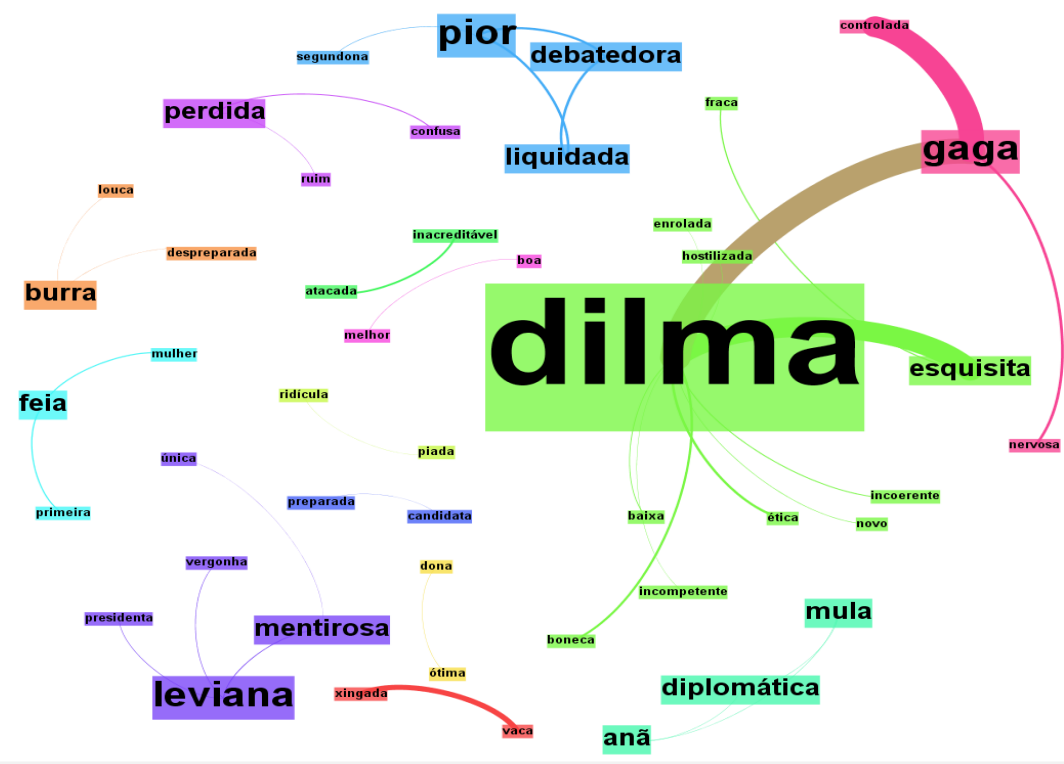

Figura 4: Coocorrências normalizadas entre os conceitos relativos aos dados de Dilma Rousseff.

Na Tabela a seguir, vemos os dados relacionados à descrição da então candidata (Tabela 5) de forma sistematizada. Como Dilma é então descrita?

Tabela 5: Dados referentes à descrição de Dilma Rousseff nos tweets

\begin{tabular}{c|c|c|c}
\hline Conceitos & Tom & Crítica & Frequência \\
\hline gaga & Crítica & Atitude no debate & 548 \\
\hline controlada & Crítica & Atitude no debate & 448 \\
\hline esquisita & Crítica & Aspecto físico & 428 \\
\hline vaca & Crítica & Caráter & 112 \\
\hline nervosa & Crítica & Atitude no debate & 66 \\
\hline mentirosa & Crítica & Caráter & 65 \\
\hline pior debatedora & Crítica & Capacidade & 48 \\
\hline
\end{tabular}




\begin{tabular}{|c|c|c|c|}
\hline liquidada & Crítica & Atitude no debate & 48 \\
\hline boneca & Crítica & Capacidade & 44 \\
\hline perdida & Crítica & Atitude no debate & 34 \\
\hline fraca & Crítica & Capacidade & 32 \\
\hline melhor candidata & Elogio & Capacidade & 25 \\
\hline feia & Crítica & Aspecto físico & 24 \\
\hline leviana & Crítica & Atitude no debate & 16 \\
\hline louca & Crítica & Capacidade & 16 \\
\hline ridícula & Crítica & Aspecto físico & 13 \\
\hline despreparada & Crítica & Capacidade & 9 \\
\hline ótima & Elogio & Atitude no debate & 8 \\
\hline preparada & Elogio & Capacidade & 8 \\
\hline boa & Elogio & Capacidade & 8 \\
\hline incompetente & Crítica & Capacidade & 8 \\
\hline anã diplomática & Crítica & Capacidade & 8 \\
\hline mula & Crítica & Capacidade & 8 \\
\hline enrolada & Crítica & Atitude no debate & 6 \\
\hline burra & Crítica & Capacidade & 5 \\
\hline
\end{tabular}

A partir dos dados apresentados, podemos observar que as críticas à Dilma Rousseff, além de mais plurais, foram mais focadas em sua capacidade, aspecto físico e caráter. Os elogios, por outro lado, foram mais concentrados em sua capacidade. É interessante observar como as desqualificações são mais fortes e em maior número (como vemos na tabela e na figura) no caso da candidata, especialmente em relação aos dados de Aécio. Como vimos, a tabela descreveu os dados quantitativos e a figura, as relações entre os mesmos. Na próxima seção, portanto, discutiremos as regularidades e irregularidades observadas nesta análise.

\subsection{Discussão}

Em primeiro lugar, podemos observar que há muito mais descrições críticas de Dilma do que de Aécio. Enquanto as críticas a Aécio dizem respeito principalmente à sua atitude no debate (há apenas um conceito, na frequência, que foca seu aspecto físico, "velho"), as críticas a Dilma são 
mais plurais. Enquanto metade delas diz respeito à sua atitude no debate (08), outra metade é direcionada à sua capacidade (08) e um terceiro grupo (04) ao seu aspecto físico. O último é a categoria "caráter", com duas referências. Em termos totais, há 1200 referências críticas à atitude no debate de Dilma, contra 489 relacionadas ao aspecto físico, 177 na categoria “caráter” e 178 na categoria capacidade. As críticas a Dilma também são muito mais contundentes que as de Aécio, especialmente porque ela é a única que é comparada a animais ("vaca" e "mula"). Observamos também que o xingamento "vaca" refere-se diretamente a uma ofensa tipicamente associada às mulheres, ao feminino, uma vez que seu masculino ("touro") não é utilizado como elemento ofensivo. Esse dado é importante porque vai ao encontro do que Zanello, Bukowitz e Coelho (2011) e Zanello e Costa (2010) demonstraram em seu trabalho. Além disso, as críticas à capacidade também são mais contundentes ("louca”). Rousseff também é a única candidata que recebe um número considerável de críticas a seu caráter ("mentirosa"). Finalmente, é importante também observar que entre as maiores críticas, estão aquelas a seu aspecto físico ("esquisita”, "feia" e "ridícula"). Novamente, observamos o caráter sexista de algumas descrições, como demonstrado por Zanello, Bukowitz e Coelho (2011) e Zanello e Costa (2010). Já os elogios (um total de 49 menções) são focados, principalmente, na sua capacidade.

Já no caso de Aécio, as críticas são mais suaves e direcionadas, principalmente à sua atuação no debate ( 975 menções). Encontramos apenas 76 menções críticas a seu aspecto físico, 76 a seu aspecto emocional e 77 com relação a sua condição social. Essas duas últimas categorias não aparecem na descrição de Dilma. As críticas mais contundentes a Aécio dizem respeito a ser "sujo" e "idiota" (mas ambas com baixíssima frequência, total de 11). Vemos, portanto, uma diferença bastante importante com relação a Dilma. Os elogios a Aécio também são muito mais presentes. Em um total de 628 menções, a maioria refere-se à sua capacidade (512) e algumas à sua atitude no debate (116). As críticas a Aécio, entretanto, são mais suaves porque, em sua maioria, não atacam diretamente sua virilidade e seu físico (no máximo chamado de "velho"). Ou seja, há um posicionamento menos sexista nessas críticas.

A análise de coocorrências e dos tweets revelou também como os conceitos estão associados, apontando melhor os elogios e críticas. Pudemos observar, por exemplo, que as principais críticas a Aécio estão associadas 
entre si, apontando para alguma mensagem que tenha sido amplamente retuitada no conjunto de dados. Alguns outros conceitos, como "forte", "arrogante" e "desrespeitoso" estão também associados a "homem". Já no caso de Dilma, há outras coocorrências importantes. Por exemplo, vemos os conceitos centrais de "leviana", "mentirosa", "presidenta" e "vergonha" como fortemente associados. Outro grupo relevante é aquele que associa "feia" e "primeira" a "mulher". Ambos esses conjuntos estão fortemente associados a tweets que receberam grande atenção e foram retuitados.

Evidentemente, também observamos forte caráter sexista em muitas críticas à então candidata, especialmente associadas à mulher (aspectos físicos e capacidade, por exemplo). Enquanto Aécio é criticado essencialmente quanto à sua atitude no debate (portanto, ele não "é", mas "está" naquele momento, agindo de uma forma determinada), Dilma é criticada também quantoà sua capacidade (ela "é" "burra", "louca", "incompetente") e aspecto físico (ela "ê" "burra”, "feia", "vaca”, "ridícula”). Embora existam também críticas à atitude no debate (principalmente quanto a ser "controlada” pelo PT e ser "gaga"), vemos que há outros conjuntos de críticas para Dilma que praticamente não existem para Aécio (caráter, capacidade e aspecto físico, principalmente). Esses dados estão relacionados com os trabalhos de Zanello, Bukowitz e Coelho (2011) e Zanello e Costa (2010), que também descrevem como ofensas e críticas podem ter viés de gênero em sua construção.

É importante compreender essas descrições também como reverberações que operam em uma esfera pública (Habermas, 1991), de característica sistêmica, que está também relacionada ao ecossistema midiático da esfera pública online (Bastos, 2011). Isso é importante porque representam dados de tweets e retweets de pessoas que discutiam os debates. Assim, essas descrições e suas reverberações são diretamente relacionadas a regularidades que são observadas nos tweets, ou ainda, "formações discursivas" no sentido de Foucault (1986). Essas formações são importantes porque, nos dados que estudamos, encontramos evidências de desconstruções dos candidatos (ambos são mais criticados do que elogiados) e de ofensas de caráter sexista (especialmente no que diz respeito à descrição da então candidata Dilma Rousseff). Assim, para descrever a candidata são usados mais elementos relativos a seu aspecto físico e comportamento sexual do que o candidato. A Aécio, as críticas são muitos mais focadas em sua atitude. 


\section{Conclusões}

Este trabalho reflete elementos discursivos presentes na sociedade no que diz respeito à reverberação do discurso político e das práticas enunciativas sobre os candidatos. Vimos, assim, que há diferenças bastante fortes nos modos através dos quais os candidatos são descritos.

Esses elementos são importantes porque mostram um viés de gênero nas descriçōes dos candidatos. Dilma é pouco elogiada e os elogios, embora focados em sua capacidade, são bastante gerais ("melhor candidata" ou "preparada"). Já os elogios a Aécio são muito mais específicos ("bom gestor") e direcionados também à sua capacidade. É nas críticas, entretanto, que observamos impactos discursivos significativos. Dilma é mais duramente criticada e suas ofensas são bastante sexistas e diretamente relacionadas a papéis de gênero. Seus elogios, por outro lado, são mais vagos e direcionados a sua capacidade no cargo. A maior parte das descrições dos candidatos, assim, são críticas. Há um conjunto muito menor de descrições positivas ou de debate sobre as capacidades dos mesmos.

A esfera pública formada pelo Twitter, assim, também reproduz relaçôes de poder importantes a partir das constituições de gênero, que têm impacto, por sua vez, no discurso político. OTwitter, assim, atua como uma esfera pública dual, onde há uma clara divisão de apoio entre os candidatos (de modo semelhante ao descrito por Conover et al., 2011) e uma divisão em termos de descriçôes ou boas ou ruins dos candidatos, mostrando também o caráter panfletário do comportamento dos usuários do Twitter.

\section{Referências}

BARDIN, L. Análise de Conteúdo. Lisboa: Ed. 70, 2004.

BASTOS, M. T. Public Opinion Revisited: The Propagation of Opinions in Digital Networks. Journal of Arab \& Muslim Media Research, 2011. Disponível em: $<$ http://www.intellectbooks.co.uk/journals/view-Article,id=12567/>. Acesso em: 09 jul. 2015.

BASTOS, M.T., RAIMUNDO, R., TRAVITZKI, R. Gatekeeping Twitter: Message Diffusion in Political Hashtags. Media, Culture \& Society, 2013. Acesso em: 09 jul. 2015. CAMPBELL, A. et al. The American voter. New York: Wiley, 1960.

CGI - Comitê Gestor da Internet. Pesquisa TICS Domicílios, 2013. Disponível em: http://www.cetic.br/publicacao/pesquisa-sobre-o-uso-das-tecnologias-deinformacao-e-comunicacao-no-brasil-tic-domicilios-e-empresas-2013/. Acesso em: 09 jul. 2015. 
CONOVER, M.D; RATKIEWICZ, J.; FRANCISCO, M.; GONÇALVES, B.; FLAMMINI, A.; MENCZER, F. Political Polarization on Twitter. Proceedings of the Fifth International AAAI Conference on Weblogs and Social Media, ICWSM, 2011. Disponível em: http://www.aaai.org/ocs/index.php/ICWSM/ICWSM11/ paper/viewFile/2847\%3Cbr/3275. Acesso em: 09 jul. 2015)

CONOVER, M.D; GONÇALVES, B.; RATKIEWICZ, J.; FLAMMINI, A.; MENCZER, F. Predicting the Political Alignment of Twitter Users. Privacy, Security, Risk and Trust (PASSAT) and 2011 IEEE. Third Inernational Conference on Social Computing (SocialCom), 2011 (p.192-199) DOI: 10.1109/PASSAT/ SocialCom.2011.34. Acesso em: 09 jul. 2015.

DEGENNE, A. \& FORSÉ, M. Introducing Social Networks. London: Sage Publications, 1999.

DOWNS, A. Uma teoria econômica da democracia. São Paulo: Edusp, 1957.

FINNEMANN, N. O. The Internet: A New Communicational Infrastructure. Papers from Centre for Internet Research (CFI). Disponível em: http://cfi.au.dk/ fileadmin/www.cfi.au.dk/publikationer/cfis_skriftserie/002_finnemann.pdf. (Acesso em: 09 jul. 2015)

FOUCAULT, M. A arqueologia do saber. Rio de Janeiro, Forense Universitária, 1986.

HABERMAS, J. The Structural Transformation of the Public Sphere: An Inquiry into a Category of Bourgeois Society (Studies in Contemporary German Social Thought). MIT Press, 1991.

LAZARSFELD, P.; BERELSON, B.; GAUDET, H. The people's choice. New York: Columbia University Press, 1948.

NEWMAN, M. E. J. The structure and function of complex networks. SIAM Rev., 45(2), 167-256, 2003. Disponível em: http://www-personal.umich.edu/ - mejn/ courses/2004/cscs535/review.pdf. Acesso em: 09 jul. 2015.

OSGOOD, C. E. The Representational Model and Relevant Research Methods. In: POOL, I. S. Trends in Content Analysis. Urbana: University of Illionois, 1959. RECUERO, R.; BASTOS, M. T.; ZAGO, G. Twitter in Political Campaigns: The Brazilian 2014 Presidential Elections. Em: BRUNS, A. (org.) Routledge Companion to Social Media and Politics, London: Routledge (2016). (no prelo)

RECUERO, R. A Conversação em Rede. Sulina, 2012.

WASSERMAN, S. \& FAUST, K. Social Network Analysis: Methods and Aplications. Cambridge: Cambridge University Press, 1994.

ZANELLO, V. e GOMES, T. Xingamentos masculinos: a falência da Xingamentos masculinos: a falência da virilidade e da produtividade virilidade e da produtividade. 
Caderno Espaço Feminino, v. 23, n. 1/2, 2010. (p. 265-280) Disponível em: http:// www.seer.ufu.br/index.php/neguem/article/view/7615/7079. Acesso em: 09 jul. 2015.

ZANELlO, V. BUKOWITZ, B; COELHO, E. Xingamentos entre adolescentes em Brasília: Linguagem, Gênero e Poder. INTERACÇÕES NO. 17, PP. 151-169 (2011). Disponível em: http://repositorio.ipsantarem.pt/ bitstream/10400.15/507/1/Q9_Valeska\%2c\%20Bruna\%20\%26\%20Elisa.pdf. Acesso em: 09 jul.2015.

Data de submissão: 16/07/2015. Data de aprovação: 02/12/2015. 